\title{
The role of the diaphragm in trunk extension in tetraplegia
}

\author{
C Sinderby, Research Fellow, P Ingvarsson MD, L Sullivan MD PhD, \\ I Wickström MD PhD, L Lindström PhD
}

\section{Departments of Neurosurgery, Neurology, Anaesthesiology and Clinical Data Processing, Sahlgrenska Hospital, S-413 45 Gothenburg, Sweden.}

Interest has been focused on the diaphragm as the all important respiratory muscle in tetraplegia for decades but its unique role as a trunk extension muscle has not been considered. This study set out to establish the relationship, if any, between the roles of the diaphragm during arm exercise and trunk flexion.

Eight male complete cervical cord injuries (CCI) patients, sitting in their wheelchairs, were studied during rest, trunk flexion and start of arm cranking. The average flow, volume, oesophageal and gastric pressures (Poes and Pga) and the myoelectric activity of the diaphragm (EMGdi) were recorded.

The EMGdi pattern changed from phasic activity at rest to continuous or almost continuous activity during trunk flexion. Patients were then either spontaneously holding their breath or breathing irregularly with rapid or shallow breaths. Also, the normalised EMGdi signal strength increased by an average of $150 \%$ and the mean Pga by about $3 \mathrm{kPa}$, while mean Poes decreased by about $0.5 \mathrm{kPa}$.

At the start of exercise, patients with poor triceps function, $<$ MRC grade 3, exhibited similar ventilatory and EMGdi changes as had been seen in trunk flexion. In patients with better triceps function, only minor changes in these variables were observed.

The findings suggest that the diaphragm acts both as a trunk extensor muscle and a respiratory muscle. During posture imbalance, the postural needs temporarily override the respiratory needs.

Key words: tetraplegia; posture; imbalance; oesophageal pressures; gastric pressures; diaphragm; electromyography.

In cervical cord injury (CCI) patients with complete lesions below the $\mathrm{C} 4$ level, there is a loss of function of the trunk muscles and sometimes also of the accessory respiratory muscles. ${ }^{1}$ This makes the patient dependent on the diaphragm as the functioning inspiratory muscle. The function of the diaphragm in CCI patients has only been studied in relation to respiration, not considering the equally unique role of the diaphragm as a trunk extension muscle in these patients.

It was recently observed that, at the start of arm cranking, CCI patients with poor triceps function changed from their usual breathing pattern to very rapid and shallow breathing, or held their breath. ${ }^{2}$ The change was accompanied by an increase in abdominal pressure and continuous myoelectric activity of the diaphragm. Such changes could not be observed at the start of arm cycling in patients with good triceps function. It appeared that the dominant use of flexor muscles during arm cycling elicited a force that bent the trunk forward. The change of breathing would then result from the contraction of the diaphragm needed to erect the trunk during the work.

Transthoracic EMG activity of the diaphragm was studied with surface electrodes in another group of patients with the same neurological impairment: increased diaphragmatic activity was registered when the patients were, unknowingly, gently pushed forward from the back. ${ }^{3}$ When the same patients voluntarily bent forward, a continuous rise in EMG activity was observed.

Transthoracic diaphragmatic EMG in 
CCI patients has earlier been studied with surface electrodes, ${ }^{4,5}$ although the validity of this method has not been fully established. It is important to ensure that interference by spastic intercostal muscle activity is avoided. Such activity in CCI patients can be elicited by movements of the rib cage. ${ }^{6}$ For this series of studies, we developed a method of recording the diaphragmatic EMG with the electrodes located in the oesophagus.

The first aim of this investigation was to analyse how trunk flexion in CCI patients affects the intrapleural and abdominal pressures, the ventilation and the diaphragmatic EMG activity. The second aim was to compare these parameters during trunk flexion and at the start of arm exercise.

\section{Method}

\section{Measurements}

Oesophageal and gastric pressure (Poes and $\mathrm{P} g a)$ representing intrapleural and abdominal pressure were measured with a balloon catheter system connected to 2 differential pressure transducers (SCMScreenmate-spezial, Erich Jaeger GmbH \& $\mathrm{Co}$ ), with atmospheric pressure as reference. Two latex balloons, each $10 \mathrm{~cm}$ in length and $3.5 \mathrm{~cm}$ in circumference, were attached to a modified quadruple-lumen Swan Ganz Pacing-TD catheter (93200H-7F, American Edwards Laboratories) $110 \mathrm{~cm}$ in length. ${ }^{7}$ The filtering influence of the catheter was corrected by enhancing the high frequency components of the pressure signals.

Diaphragmatic EMG signals (EMGdi) were obtained by means of 2 cobalt electrodes $\left(\right.$ Elgiloy $^{\mathrm{TM}}$ ) situated $15 \mathrm{~mm}$ apart. An anchoring balloon $3 \mathrm{~cm}$ in length and $3.5 \mathrm{~cm}$ in circumference was attached $1.5 \mathrm{~cm}$ distally to the most distal EMG electrode on the catheter. The EMGdi signals were amplified (Medelec AA6 Mk III with preamplifier) and band pass filtered with cut off frequencies of 8 and $800 \mathrm{~Hz}$ respectively.

Flow was measured at the mouth with a pneumotachograph (Jaeger Screenmate, $1 / \mathrm{E} 05856$, resistance $36 \mathrm{~Pa} / \mathrm{l} / \mathrm{s})$. Volume was obtained by integration of flow.

\section{Protocol}

Eight men with complete cervical cord injuries who had given their informed consent were studied after a small standardised breakfast. Patient characteristics are presented in Table 1.

In order to compare the strategies of breathing during trunk flexion and exercise, the patients were ranked according to the strength of their triceps brachii muscles assessed on a $0-5$ scale (British Medical Research Council, MRC) ${ }^{8}$

All tests were performed with the subjects sitting in their own wheelchairs. The catheter was introduced via the nose to a distance of $80 \mathrm{~cm}$. The anchoring balloon was then filled with $5 \mathrm{ml}$ of air and the

Table 1 Characteristics of patients in the study, and work load

\begin{tabular}{|c|c|c|c|c|c|c|c|c|}
\hline $\begin{array}{l}\text { Patient } \\
\text { no }\end{array}$ & $\begin{array}{c}\text { Age/Sex } \\
\text { (years) }\end{array}$ & $\begin{array}{l}\text { Height } \\
(\mathrm{cm})\end{array}$ & $\begin{array}{l}\text { Weight } \\
(\mathrm{kg})\end{array}$ & $\begin{array}{l}\text { Time since } \\
\text { injury } \\
\text { (years) }\end{array}$ & $\begin{array}{l}\text { Level of } \\
\text { injury }\end{array}$ & $\begin{array}{l}\text { Trice } \\
\text { MRC } \\
\text { right }\end{array}$ & $\begin{array}{l}\text { ength } \\
0-5 \\
\text { left }\end{array}$ & $\begin{array}{c}\text { Work } \\
\text { load } \\
\text { W }\end{array}$ \\
\hline $1^{*}$ & $34 / \mathrm{M}$ & 186 & 63 & 11 & C6 & 0 & 0 & 10 \\
\hline 2 & $31 / \mathbf{M}$ & 193 & 72 & 10 & C5-C6 & 0 & 0 & 10 \\
\hline $3^{* *}$ & $37 / \mathrm{M}$ & 180 & 70 & 2 & C5-C6 & $1-2$ & 2 & 10 \\
\hline 4 & $23 / \mathrm{M}$ & 178 & 61 & 2 & C6-C7 & 2 & 3 & 10 \\
\hline 5 & 26/M & 175 & 69 & 6 & C8 & $4-5$ & $4-5$ & 20 \\
\hline 6 & $48 / \mathrm{M}$ & 176 & 80 & 17 & $\mathrm{C} 8$ & $4-5$ & $4-5$ & 10 \\
\hline 7 & $25 / \mathrm{M}$ & 170 & 62 & 3 & C6-C7 & 5 & 4 & 10 \\
\hline 8 & $31 / \mathbf{M}$ & 174 & 85 & 13 & $\mathrm{C} 7-\mathrm{C} 8$ & 5 & 5 & 10 \\
\hline
\end{tabular}

*anterior rhizotomy Th12-S1 (1984)

** constantly wearing an elastic abdominal binder 
catheter was withdrawn until the balloon stopped at the cardia. To fix the anchoring balloon in this position, a small weight was attached to the catheter just proximal to the nostrils. Before every manoeuvre, the oesophageal and abdominal balloons were deflated until a negative pressure of $2 \mathrm{kPa}$ was obtained and then inflated with $0.5 \mathrm{ml}$ and $2.5 \mathrm{ml}$ of air, respectively. ${ }^{9}$ The test situation is illustrated in Figure 1.

\section{Rest}

All patients were sitting in a relaxed position, leaning backwards, with their arms hanging loosely by their sides, breathing through the pneumotachograph and provided with a nose clip.

\section{Trunk flexion}

The patients were instructed to cross their arms over their chest and then bend forward to the farthest position they could maintain without falling. In this position, the angle between an estimated line from the acromion to the superior anterior iliac spine and the vertical plane was measured. During flexion, the pneumotachograph was hanging from a rigid lever in a $40 \mathrm{~cm}$ long elastic band, thus not interfering with the patient's movement. EMGdi, Poes and Pga were measured in all patients. Flow and angle were not measured in patients nos. 3 and 6 .

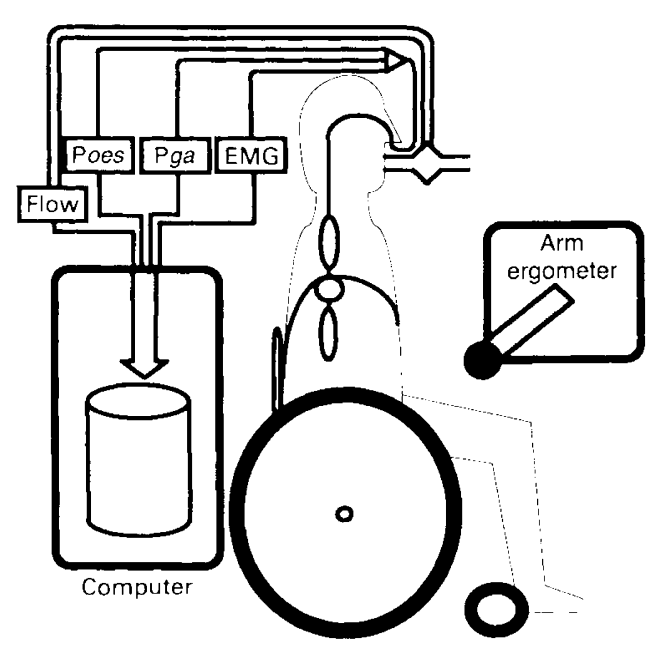

Figure 1 The test set-up.

\section{Exercise}

Arm exercise was performed on an arm ergometer (RE 820 Rodby Electronics). The crank rate was $60 \mathrm{r} / \mathrm{m}$.

Before work, the patients were sitting in front of the arm ergometer with their hands on the handgrips; when necessary, their hands were fixed. After 30 seconds of rest, they started to work at approximately $20 \%$ of the maximal load they had sustained for 4 minutes in a pilot test. The work loads are presented in Table 1.

All patients breathed through the pneumotachograph which was mounted on a rigid lever and fixed in the desired position for each subject before they started the test. Small movements of the head were allowed by a flexible joint near the mouth.

\section{Data processing and analysis}

During each manoeuvre, flow and pressure signals were collected with a sampling frequency of $125 \mathrm{~Hz}$ and EMGdi with $2 \mathrm{kHz}$. All signals were processed and stored in a digital computer (PDP-11/70, Digital Equipment Corporation). To obtain characteristics of the different test situations, and to compare them, simultaneous values of flow, volume, average oesophageal and gastric pressures were calculated from the following 3 periods: 10 seconds at rest, the first 10 seconds of exercise and 10 seconds when the trunk flexion reached the outermost position. From the same time periods, contiguous EMGdi signal sequences of $255 \mathrm{~ms}$ were collected where clear EMGdi signals were present and no cardiac activity was observed. For each sequence, the root mean square values (RMS) of the EMGdi were calculated. The EMGdi signals were edited on a video monitor. In order to avoid possible disturbances and individual signal differences, relative changes in EMGdi activity (RMS) were calculated as:

$$
\Delta \mathrm{EMG} d i \equiv \frac{\left(\mathrm{EMG} d i_{\text {activity }}-\mathrm{EMG} d i_{\text {rest }}\right)}{\mathrm{EMG} d i_{\text {rest }}}
$$

\section{Statistical analysis}

Values are presented as mean \pm standard deviation. Changes in measuring variables 
were analysed using paired t-tests. $P$-values less than $5 \%$ were considered to be significant.

\section{Results}

\section{Rest versus trunk flexion}

The average angle obtained during trunk flexion was $17^{\circ}\left(\mathrm{SD}=12^{\circ}\right)$. The EMGdi pattern changed from phasic activity at rest to continuous or almost continuous activity during trunk flexion. Typical EMGdi, Poes, $\mathrm{Pg} a$, flow and volume tracings are shown in Figure 2. The increase in mean $\triangle \mathrm{EMG} d i$ in all patients was on average $150 \%$ (SD $=$ $120 \%, p<0.005)$. Mean Pga increased in all patients, on average by $3.1 \mathrm{kPa}(\mathrm{SD}=$ $1.4 \mathrm{kPa}, p<0.0005)$ and mean Poes declined on average by $0.45 \mathrm{kPa}(\mathrm{SD}=$ $0.22 \mathrm{kPa}, p<0.0005)$.

During trunk flexion, the patients were either holding their breath or breathing irregularly with rapid and shallow breaths. At the outermost trunk flexion, Pga reached a plateau and the breathing pattern stabilised at a higher breathing rate in some

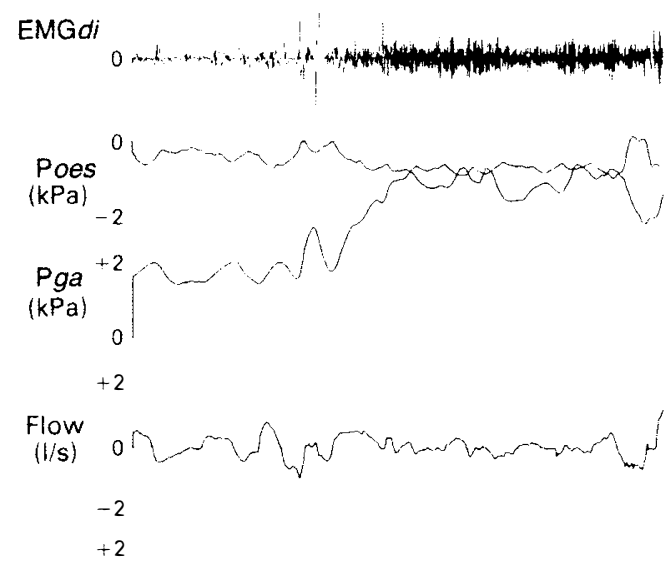

Volume

(I)

$\cdots 2$

34.0

50.0

Figure 2 EMGdi, Poes, Pga, flow and yolume tracings during trunk flexion in patient no. 6 . There is a clear transition from tidal breathing with phasic EMGdi to an irregular breathing pattern, continuous EMGdi activity and markedly increased Pga. patients, while others continued their irregular rapid and shallow breathing or breath-holding until trunk flexion was stopped.

\section{Rest versus exercise}

Patients with triceps function less than MRC grade 3 changed their ventilatory pressures and EMGdi patterns in a way similar to that described for all patients during trunk flexion. In patients with better triceps function, only minor changes in ventilatory pressures and EMGdi patterns were observed. Two typical tracings are presented in Figures 3 and 4. They exhibit EMGdi pattern, flow, volume, Poes and Pga during the last breaths before and the first breaths during exercise.

Comparison of trunk flexion and the exercise indicated a decreasing difference in mean Pga with reduced triceps function as detailed in Figure 5 (upper panel). A similar tendency was observed in mean $\triangle E M G d i$, except for patient no. 7 (Figure 5, middle

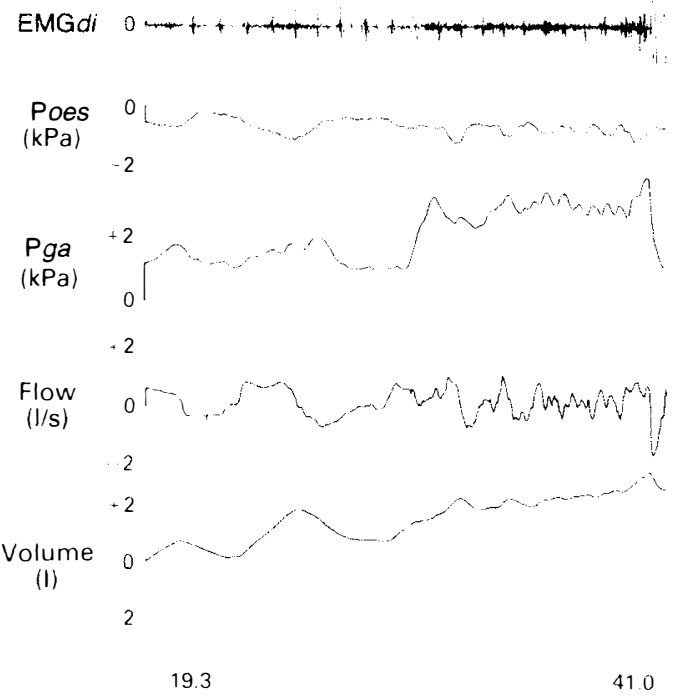

Figure 3 EMGdi, Poes, Pga, flow and volume tracings during the last 2 breaths before and the first breath during exercise in patient no. 2 . The last normal breath at rest is followed by prolonged breath with an increase in Pga. This is accompanied by a change to rapid and shallow breathing with continuous EMGdi activity and superimposed phasic activity. 


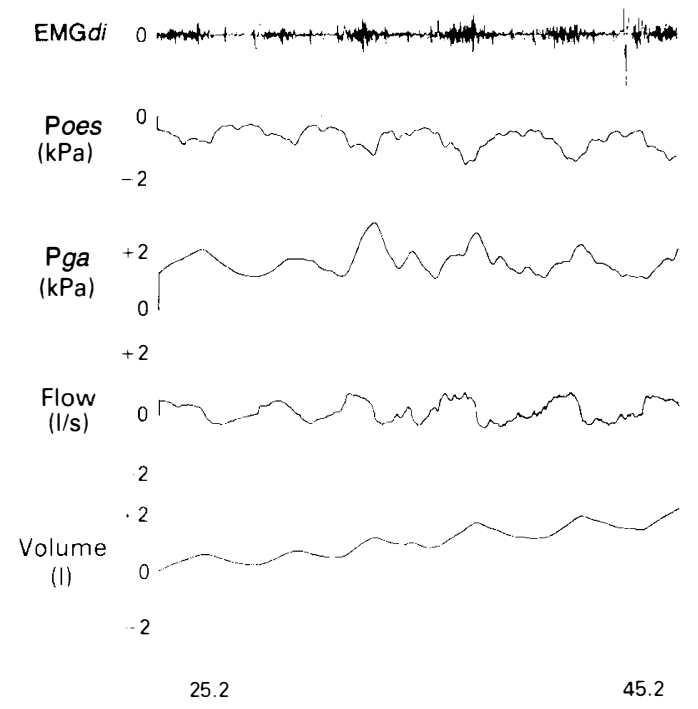

Figure 4 EMGdi, Poes, Pga, flow and volume tracings during the last 2 breaths before and the first 3 breaths during exercise in patient no. 8 . Only minor changes in the measured variables are seen at the start of exercise.

panel). The decline in mean Poes was more pronounced during trunk flexion than during exercise (Figure 5, lower panel).

\section{Discussion}

The number of patients available was limited. Furthermore, the experiments were not altogether effortless for the investigators and not very convenient for the patients, who were therefore difficult to recruit. Thus, we limited the number of patients to the minimum necessary for achieving conclusive data. The statistics used consider the sample size in the analysis. We think that this yielded relevant information.

The study indicates that truck flexion in complete CCI patients markedly affects respiration, intrapleural and abdominal pressures and the myoelectric activity of the diaphragm. In all patients, the ordinary phasic EMGdi pattern changed to continuous diaphragmatic EMG activity. At the same time, there was a clear increase of $\Delta \mathrm{EMG} d i$, Poes and Pga. Except for Poes,

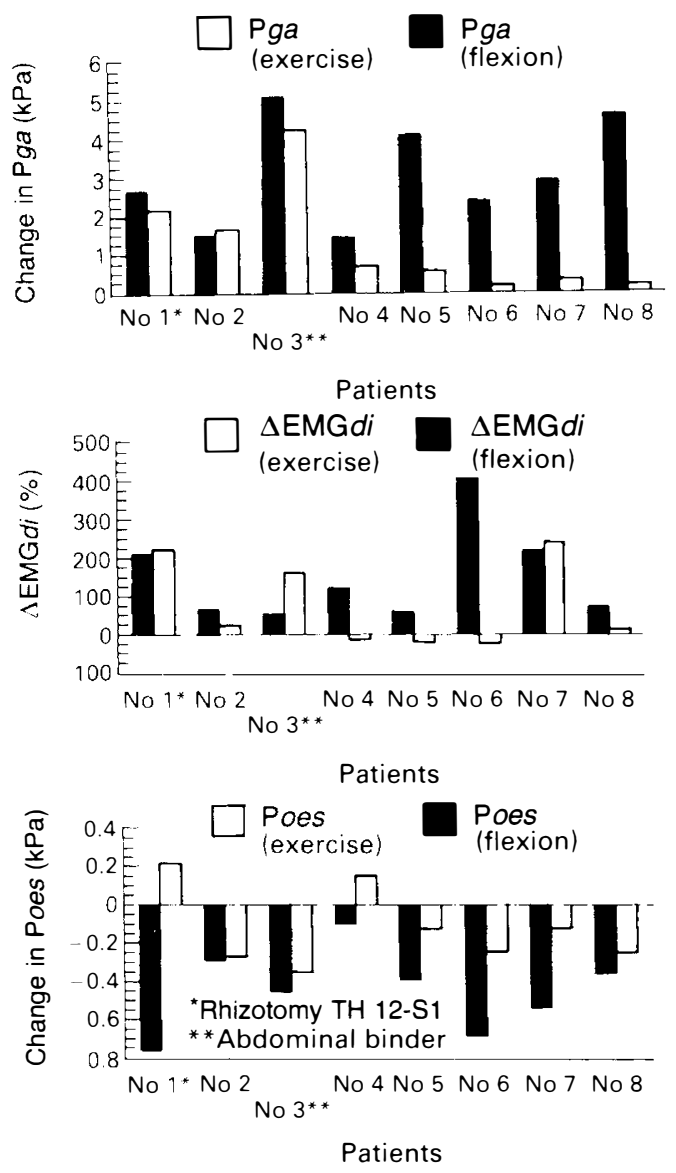

Figure 5 Changes in each patient during trunk flexion and start of exercise: Pga, (upper panel), EMGdi (middle panel) and Poes (lower panel). Patients are ranked from left to right according to increasing triceps function.

these abnormalities were found only when patients with poor triceps function started arm cycling exercise. Diaphragmatic activities recorded in this study do not always relate to ventilatory work. This is obvious, as some patients held their breath in the peak period of diaphragmatic EMG activity.

The fact that CCI patients can perform and control a trunk flexion that exceeds the centre of gravity and actively return to an upright position implies that the diaphragm acts as a trunk extensor in these patients. Further, this manoeuvre is reflected by irregular respiratory flow and by increase in Poes, Pga and diaphragmatic EMG. The 
angle during trunk flexion varied irrespective of the patients' lesion levels. Also, there were no changes in respiratory parameters during trunk flexion relating to degree of paralysis. When CCI patients with paralysed trunk muscles and poor triceps function start to revolve the arm cycle, the pull in one arm generates a forward action movement on the trunk for which the incapability to extend the elbow in the other arm cannot compensate. The imbalance between elbow flexor and extensor muscles will therefore force the trunk forward in a movement similar to trunk flexion. The similarity between the registered respiratory parameters in all patients during trunk flexion and patients with poor triceps function at start of exercise further underlines that the diaphragm acts as a trunk extensor.

We hypothesised that the rise in abdominal pressure after diaphragmatic contraction produces an expansion of the abdominal cavity. This prevents the lower thorax aperture from narrowing the distance to the pelvis, as illustrated by the situation when an inflated ball is pressed into the abdominal pit. When the diaphragm increases the abdominal pressure, the expanding forces within the abdomen will act to erect the trunk. This reasoning assumes a very low abdominal compliance for the patient group. In order to test the effects of low abdominal pressure, patient no. 4 , with the lowest $\mathrm{Pga}$ during trunk flexion $(2.6 \mathrm{kPa})$, was given a $15 \mathrm{~cm}$ wide, soft, non elastic abdominal binder over the umbilicus. The binder was tightened only so that the increase of the end-expiratory abdominal pressure was $0.5 \mathrm{kPa}$. With the binder applied, the patient could lean forward to $25^{\circ}$, compared to $10^{\circ}$ without the binder. During forward leaning the mean $\mathrm{Pga}$ was $4.4 \mathrm{kPa}$ compared to $2.6 \mathrm{kPa}$ without the binder. The increase in EMGdi was $120 \%$ and unchanged compared to the situation without the binder. This finding indicates that the mechanical situation of the diaphragm to act as a trunk extensor can be improved by reduction of abdominal compliance. The additional increase in Pga during diaphragmatic shortening will then produce a firmer mechanical support. A high increase in abdominal pressure was also seen during trunk flexion and exercise in patient no. 3 , who constantly wore an elastic abdominal binder.

A possible contributory factor controlling trunk flexion is the hypertonic extensor muscles of the back and hip regions in tetraplegic patients. This concept was supported by findings in a patient (no. 1) who had undergone an anterior rhizotomy from Th12 to S1 and was unable to flex his trunk beyond the vertical plane.

In an early study, inspiratory myoelectric activity of the intercostal muscles was registered and interpreted to indicate spasticity. ${ }^{6}$ The possibility of such interfering activity must be considered. The similarity between our oesophageal registrations in this study and our earlier ${ }^{3}$ transthoracic EMG registrations indicates that the latter kind of registration is sufficient for detection of differences between phasic and continuous diaphragmatic EMG activity. Our faith in the accuracy of transthoracic registration is further strengthened by our experience that patients still in traumatic shock after cervical cord injuries, and thus without spastic intercostal myoelectric activity, ${ }^{6}$ exhibit the same EMGdi pattern as was seen in the present study when they are moved a few degrees into trunk flexion from the straight sitting position.

In conclusion, the study showed that the EMGdi pattern changes from phasic to stronger continuous activity when tetraplegic patients bend forward. Together with this change of EMGdi activity, there is a marked increase in abdominal pressure. The same EMGdi signal pattern was identified when tetraplegics with poor triceps function were arm cycling. The findings imply that the diaphragm acts as a trunk extensor muscle and a respiratory muscle. During posture imbalance, the postural needs temporarily override the respiratory needs.

\section{Acknowledgements}

This study was supported by grants from the King Gustav V Foundation, the National Association of People Disabled by Road Accidents and Polio, the Folksam Insurance Company, the Association of Neurological Disabled, Glaxo Inc. and the Greta and Einar Asker Foundation. 


\section{References}

1 Estenne M, De Troyer A (1985) Relationship between respiratory muscle electromyogram and rib cage motion in tetraplegia. Am Rev Respir Dis 132, 53-59.

2 Sinderby C, Ingvarsson P, Sullivan L, Wickström I, Lindström L (1990) Work of breathing in tetraplegic subjects during exercise: a preliminary report. Proceedings of the 3rd International Physiotherapy Congress, Hong Kong: 541-546.

3 Sinderby C, Ingvarsson P, Sullivan L, Wickström I, Lindström L (1990) Postural influence on motoric activity in the diaphragm in tetraplegia. Proceedings of the 3rd International Physiotherapy Congress, Hong Kong: 619-624.

4 Gross D, Ladd HW, Riley EJ, Macklem PT, Grassino A (1980) The effect of training on strength and endurance of the diaphragm in quadriplegia. Am J Med 6, 27-35.

5 De Troyer A, Heilporn A (1980) Respiratory mechanics in quadriplegia. The respiratory function of the intercostal muscles. Am Rev Respir Dis 22, 591-600.

6 Guttmann L, Silver J (1965) Electromyographic studies on reflex activity of the intercostal and abdominal muscles in cervical cord lesions. Paraplegia 3, 1-22.

7 Javaheri S, Vinegar A, Smith J, Donovan E (1987) Use of a modified Swan-Ganz pacing catheter for measuring Pdi and diaphragmatic EMG. Pflügers Arch 408, 642-645.

8 Janda W (1977) Muskelfunktionsdiagnostik. Studentlitteratur, Lund, Sweden: 299.

9 Milic-Emili J (1984) Techniques in the life sciences, P4/II, Respiratory physiology, P 412. Elsevier Scientific Publishers, Ltd, Ireland: 1-22. 